\title{
Communicator credibility and persuasian
}

\author{
JAMES McGARRY* and CLYDE HENDRICK† \\ Kent State University, Kent, Ohio 44242
}

\begin{abstract}
Prior research has usually found a positive relationship between a communicator's perceived credibility and his persuasiveness. An experiment was designed to test the hypothesis that the perceived vested interest of a speaker, the position the speaker advocated, and the social similarity between audience and speaker would influence attributions of credibility and affect the speaker's persuasiveness. Three variables were manipulated in a 2 by 2 by 2 factorial design. Ss read a speech that either favored (pro) or opposed (con) student voting rights; the speech was attributed to a speaker who was either similar (student) or dissimilar (townie) to the student audience and who either had a vested interest (running for elective office) or had no vested interest (merely giving his opinion) in the position he advocated. As predicted, the similarity of the speaker to the audience, the vested interest of the speaker, and the position advocated in the speech strongly influenced attributions of credibility. However, in contrast to much previous research, persuasion was found to be relatively independent of the variation in the speaker's perceived credibility. It was suggested that the failure of attributions of credibility to relate to persuasion may have been due to the high degree of ego involvement for the $S s$ in the topic of student voting rights.
\end{abstract}

Since Aristotle, persuasion has been interpreted partially in terms of the personal characteristics or credibility of the communicator. Indeed, credibility, defined as expertness and trustworthiness (Hovland, Janis, \& Kelley, 1953), has traditionally been found to be a major determinant of the effectiveness of a communication. All other things being equal, the higher the credibility of a speaker, the greater the opinion change of an audience.

There is accumulating evidence that defining credibility in terms of general expertness and trustworthiness is an oversimplification and may be misleading (Walster \& Festinger, 1962; Brock \& Becker, 1965; Walster, Aronson, \& Abrahams, 1966; Mills \& Jellison, 1967). One important variable is the vested interest the communicator (regardless of his general credibility) has in the position he advocates. Walster, Aronson, and Abrahams (1966) predicted and found that, when his vested interest was salient, a communicator, regardless of his general prestige, was seen as more credible and was more effective when arguing for a position opposed to his own best interest than when advocating a position obviously in his own vested interest.

Several studies have varied the communicator's purported perception of the audience. Walster and Festinger (1962) found that Ss were more influenced by a message when they thought the speaker was unaware that he was overheard and, therefore, could not have persuasive intentions; but this effect occurred only when the message was personally involving. However, since the involving communication argued in favor of a position desirable to the Ss, it is unclear why the regular

*This article is based on a thesis submitted to Kent State University in partial fulfillment of the requirements for a Master of Arts degree.

† Requests for reprints should be sent to Clyde Hendrick, Department of Psychology, Kent State University, Kent, Ohio 44242 . communication was less effective. In a similar vein, Brock and Becker (1965) found that an overheard communication was more effective than a regular communication when the topic was involving and the conclusions desirable, but not when the communication was uninvolving or uninvolving and undesirable.

In an attempt to explain Walster and Festinger's and Brock and Becker's results, Mills and Jellison (1967) suggested that $\mathrm{Ss}$ listening to an involving communication with desirable conclusions who thought that the communicator was aware that they were listening (the regular communication) may have assumed that the communicator knew that the communication would be desirable to the Ss. However, when the Ss thought they had merely overheard the communicator, there was little reason to suspect that they assumed that the communicator was aware that the communication was desirable to them. Mills and Jellison hypothesized and found that, when the audience was aware that the communicator thought that the communication was desirable to the audience, Ss judged the communicator as less sincere and were less persuaded than in a condition in which the communicator thought that the communication was undesirable to the audience.

Clearly, the traditional notion concerning global communicator credibility and communication effectiveness is inadequate. Among other things, the content of the message, the intentions of the communicator, and the self-interest of the communicator have been found to influence the effectiveness of the communication.

An experiment was designed to test the hypothesis that the perceived vested interest of the speaker, the position advocated by the speaker, and the social similarity of the S audience to the speaker will influence attributions of credibility and the communicator's persuasive effectiveness. It was hypothesized that a speaker who was not a student but who had a vested interest in presenting himself favorably to a student 
audience would be judged more credible and would be more persuasive when he gave a speech against the position commonly held by the student audience. However, when the same speaker merely stated his opinion and had no special reason to present himself favorably to the audience, it was predicted that the speaker would be rated as more credible and would be more persuasive when he gave a speech favoring the position commonly held by the audience. When the speaker was a student, it was expected that he would be judged most credible and would be most persuasive when he gave a speech favoring the position held by the student audience.

\section{METHOD}

\section{Overview and Design}

Six groups of approximately $30 \mathrm{Ss}$ participated in the experiment, which was described as a person perception study. Each $S$ read a paragraph containing various background information about a speaker and then read a speech concerning student voting rights in local elections that was purportedly given to one of the various student groups on campus. The study was conducted before students obtained the legal right to vote in local elections. Prior to reading these materials, Ss were instructed to read carefully, so that they could answer some questions concerning their impressions of the speaker and some recall questions on the content of the speech. After reading the speech, each $S$ completed several questionnaires designed to measure attitude, perceived credibility, and recall.

Three variables were manipulated in a 2 by 2 by 2 factorial design. The position advocated by the speaker was manipulated by having Ss read a speech either favoring (pro) or opposing (con) student voting rights in local elections. The similarity of the speaker to the audience was varied by presenting the speaker as either a local citizen (townie, dissimilar to Ss) or a student (student, similar). The self-interest of the speaker was manipulated by presenting the speaker as either running for local office (running) or simply giving his opinion on student voting rights (opinion). The resulting eight conditions were: pro-townie-running, pro-townie-opinion, pro-student-running, pro-student-opinion, con-townie-running, con-townie-opinion. con-student-running, and con-student-opinion.

\section{Subjects}

One hundred and sixty male and female students from an introductory psychology course at Kent State University participated as Ss in the experiment. Envelopes containing the materials for the experiment were randomly distributed within each group of Ss. Due to their failure to answer manipulation check questions correctly, an additional 21 students were not included as $\mathrm{Ss}$ in the data analyses.

\section{Procedure}

The $E$ greeted the $S s$ and gave them a brief introduction to the purpose of the study. Ss were told that they would be participating in a person perception study and that their task would simply be to form an impression of a person based on the information that they received about that person. The details of the procedure were described to $S$ s. The $L$ then distributed envelopes containing a page of general instructions, a paragraph that gave the background information on the speaker, and the text of the speech that purportedly had been previously given to a student audience. The Ss were told that they had 10 min to read the contents of the envelope.

\section{Manipulation of the Variables}

Manipulation of the position of the speaker (pro or con) was achieved by having the Ss read a speech that either favored or opposed student voting rights in local elections. Both speeches addressed the same issues and were constructed to differ only in the position advocated. Manipulation of the similarity of the speaker (townie or student) and the vested interest of the speaker (running or opinion) was accomplished by varying the content of the paragraph giving background information on the speaker. These two variables were manipulated in the paragraph as follows.

$S s$ in the townie/running for office conditions received the following information: "The speech you are about to read was delivered to a recent student meeting on student voting rights. The speaker is $\mathrm{Mr}$. William Collins, a local merchant who is a candidate for a seat on Kent's City Council. This speech is one of a number of addresses that Mr. Collins has presented to various student organizations during his active campaign for City Council."

Ss in the townie-opinion conditions received the following information: "The speech you are about to read was delivered to a recent student meeting on student voting rights. The speaker is Mr. William Collins, a local merchant who was asked to present his views on the issue. Mr. Collin's speech is one of a number of addresses that have been presented to various student organizations by different townspeople."

Ss in the student/running for office conditions received the following information: "The speech you are about to read was delivered to a recent student meeting on student voting rights. The speaker is Bill Collins, a KSU senior who is a candidate for a seat on Kent's City Council. This speech is one of a number of addresses that $\mathrm{Mr}$. Collins has presented to various student organizations during his active campaign for City Council."

$\mathrm{S} s$ in the student-opinion conditions received the following information: "The speech you are about to read was delivered to a recent student meeting on student voting rights. The speaker is Bill Collins, A KSU senior who was asked to present his views on the issue. Mr. Collins' speech is one of a number of addresses that have been presented to various student organizations by different students."

\section{Dependent Measures}

After the allotted $10 \mathrm{~min}$ for reading the materials. Ss were requested to put them in the envelope. The $E$ then distributed a packet of three questionnaires and asked the Ss to read and answer each questionnaire carefully. The first questionnaire was a 15-item impression index consisting of 15 trait adjectives, each rated on a 9-point scale with appropriate end labels. The index measured the $S s^{\prime}$ impression of the speaker's trustworthiness, expertness, likability, credibility, etc.

The second questionnaire was a nine-jtem subjective feeling index that measured the Ss' attitude on the topic of the speech. The attitude items included statements assessing the belief that students should have the right to vote in local elections, that local citizens were against student voting rights, etc. Each item was rated on a 5-point scale with appropriate end labels. Six of the items were phrased in the con direction and the remaining three were phrased in the pro direction.

The third questionnaire was an 11-item multiple-choice speech recall questionnaire. The first nine items measured the Ss' recall of the content of the speech and the last two items served as manipulation checks. One item asked what position the speaker advocated and the second item asked whether the speaker was a student or a townie who was running for office or just giving hi opinion. Ss who failed to answer either of the last two questions correctly were not included in the analy'ses.

\section{RESULTS}

It was predicted that a townie speaker running for 
office would be evaluated more favorably and be more persuasive when giving a speech against student voting rights than when giving a speech in favor of student voting rights. Just the opposite was expected, however, when the townie speaker was merely giving his opinion. Thus, for townie speakers the pro-con direction of the speech was expected to interact with speaker's vested interest (running-opinion). No interactions were predicted for student speakers, but it was expected that a student giving a speech favoring student voting rights would be judged more favorably and would be more persuasive than when he gave a speech opposing student voting rights. The results for attributions of credibility are presented first, followed by the attitude and recall results.

\section{Impression Index Ratings}

A 2 (pro-con) by 2 (townie-student) by 2 (running-opinion) analysis of variance was performed on each of the 15 traits from the impression index. Several main effects and interactions were found. The position the speaker advocated influenced ratings of the speaker on five of the impression items. A speaker who gave a pro speech was rated significantly more likable ( $p<.0003)$, knowledgeable $(p<.04)$, accommodating $(\mathrm{p}<.0000)$, obliging $(\mathrm{p}<.001)$, and opportunistic $(p<.0003)$ than a speaker who gave a con speech.

The social similarity of the speaker to the Ss was also found to affect attributions of credibility. A student speaker was judged to be more honest $(\mathrm{p}<.05)$, sincere $(\mathrm{p}<.0006)$, truthful $(\mathrm{p}<.03)$, believable $(\mathrm{p}<.007)$, knowledgeable $(p<.005)$, intelligent $(p<.0001)$, expert $(\mathrm{p}<.02)$, and less self-centered $(\mathrm{p}<.02)$ than a townie speaker.

The vested interest of the speaker also influenced the speaker's perceived credibility. A speaker who was running for office was rated as more knowledgeable $(p<.04)$, expert $(p<.01)$, accommodating $(p<.04)$, and opportunistic $(\mathrm{p}<.0003)$ than a speaker who was merely stating his opinion.

The speaker's vested interest (running-opinion) and the position he advocated (pro-con) interacted on several traits to determine how favorably the speaker was rated. A speaker who gave a pro speech that was his opinion and a speaker who was running for office and gave a con speech were rated as more likable $(\mathrm{p}<.05)$, honest $(\mathrm{p}<.01)$, sincere $(\mathrm{p}<.007)$, truthful $(\mathrm{p}<.01)$, and less self-centered $(p<.05)$ than a speaker who was running for office and gave a pro speech or a speaker who gave a con speech that was his opinion.

Following the initial analyses for individual traits, a total impression index was calculated for each $\mathbf{S}$ by reversing the scores of the six negative traits (opinionated, accommodating, obliging, opportunistic, unconventional, and self-centered) and adding the scores for all 15 impression items. The only significant effect was that students were rated more favorably than

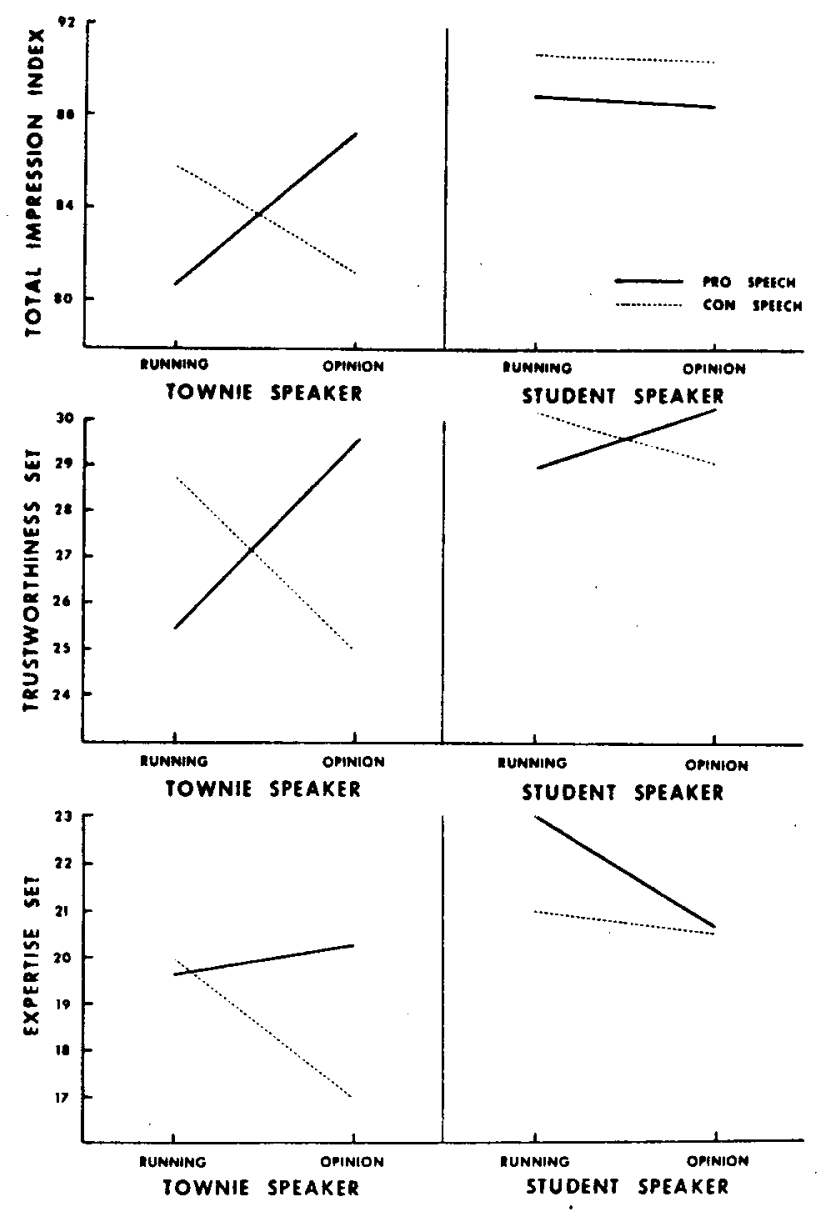

Fig. 1. Total impression index (top panel), trustworthiness set (middle panel), and expertise set (bottom panel) as function of townie-student, running-opinion, and pro-con direction of speech.

townies $(p<.0009)$. However, the pro-con running-opinion interaction was marginally significant $(p<.09)$ in the predicted direction. Speakers who were running for office were rated higher when they gave a con speech, but speakers giving their opinion were judged more favorably when they gave a pro speech. The triple interaction was also marginally significant $(p<.10)$. For townie speakers the results were in the predicted direction. A townie received higher ratings if he was running for office and gave a con speech or if he was giving his opinion and gave a pro speech. If the speaker was a student, it made little difference whether he gave a pro or a con speech or if he was running for office or just giving his opinion.

Since interactions were predicted only in the townie condition, a 2 (pro-con) by 2 (running-opinion) analysis of variance was performed on the data for townie speakers. As expected, townies were rated more favorably when they were running for office and gave a con speech and when they gave a pro speech that was their opinion $(p<.02)$. The nature of the effects for the total impression index may be seen in the top panel of Fig. 1. 
Table 1 Means for Attitude Items

\begin{tabular}{cccc}
\hline $\begin{array}{c}\text { Attitude } \\
\text { Item }\end{array}$ & $\begin{array}{c}\text { Pro } \\
\text { Speech }\end{array}$ & $\begin{array}{c}\text { Con } \\
\text { Speech }\end{array}$ & $\begin{array}{c}\text { p Value of } \\
\text { Difference }\end{array}$ \\
\hline 1 & 4.21 & 2.67 & .0000 \\
2 & 3.62 & 3.80 & .16 \\
3 & 2.90 & 3.68 & .0000 \\
4 & 4.06 & 3.67 & .01 \\
5 & 2.15 & 3.60 & .0000 \\
6 & 3.07 & 3.35 & .04 \\
7 & 3.11 & 3.35 & .06 \\
8 & 3.72 & 2.87 & .0000 \\
9 & 2.95 & 3.15 & .14 \\
Sum & 30.21 & 24.28 & .0000 \\
\hline
\end{tabular}

Note-The sum score was computed in a pro direction. Means for individual items have not been reversed.

In an attempt to define more clearly the effects for credibility, namely, trustworthiness and expertise, two subsets of impression items were summed and analyzed separately. Honest, truthful, sincere, and believable (trustworthiness set) were selected as a measure of trustworthiness; and the items knowledgeable, expert on the topic, and intelligent (expert set) were assumed to be a measure of the speaker's expertise. A significant townie-student main effect $(\mathrm{p}<.002)$ and a Pro-Con by Running-Opinion interaction $(\mathrm{p}<.003)$ were obtained for the trustworthiness set. Students were judged more trustworthy than townies, and, as predicted, speakers in the pro-opinion and the con-running conditions were judged more trustworthy.

All three main effects and the triple interaction were significant for the expert set. A speaker who gave a pro speech was seen as having greater expertise than a speaker who gave a con speech $(p<.02)$. A student speaker was judged to have greater expertise than a townie speaker $(\mathrm{p}<.0005)$. A speaker who was running for office was perceived as having greater expertise than one who was merely giving his opinion $(p<.01)$. The triple interaction followed the predictions of the study perfectly. A student speaker received slightly higher expertise ratings when he gave a pro speech and was running for office. A townie speaker, however, was seen as slightly more expert when he was running for office and gave a con speech and considerably more expert when he gave a pro speech that was his own opinion $(p<.01)$. The nature of the effects for the trustworthiness set and expertise set may be found in the middle and bottom panels of Fig. 1, respectively.

\section{Attitude Items}

Of the nine attitude items, six showed a highly significant main effect for the position advocated by the speaker. The means and $p$ values for the pro-con effect are shown in Table 1 for each attitude item as well as for the sum of all nine items. Ss who read a pro speech were more favorable toward student voting rights than Ss who read a con speech. Contrary to expectation, none of the interactions were significant. Although the manipulations had strongly interactive effects on the attributions of trustworthiness and expertise, they had no such effects on persuasion.

A total attitude score was computed by reversing the scores for the six items phrased in a con direction and adding them to the three pro items. The only significant result was a pro-con main effect. Ss who read a pro speech were more in favor of student voting rights than Ss who read a con speech $(p<.0000){ }^{1}$

\section{Recall Questions}

The total number of correct recall questions was computed for each S. Although there were no significant differences, Ss who read a con speech had slightly better recall than $S s$ who read a pro speech $(p<.07)$.

\section{DISCUSSION}

The results of the study offer partial support for the hypothesis that the perceived vested interest of the speaker, the position the speaker advocates, and the social similarity of the $\mathrm{S}$ audience to the speaker influence attributions of credibility. However, only the position advocated affected the communicator's persuasiveness. Ss clearly attributed to different speakers varying amounts of credibility; however, these attributions had no mediational effect on persuasion. Regardless of how credible a speaker was judged to be, Ss who read a pro speech were significantly more in favor of student voting rights than Ss who read a con speech.

The results involving attributions of credibility followed the predictions of the study quite well. As expected, a student speaker was generally judged more favorably than a townie speaker irrespective of vested interest (running-opinion) or the position advocated. It seems that Ss assumed similarity between themselves and the student speaker and that this assumed similarity was more important than the other factors.

The predicted interaction of Vested Interest by Position Advocated was found for a townie speaker. Since it was known that students generally felt that townspeople were opposed to students voting in local elections, presumably Ss surmised that a townie running for office was in favor of student voting rights only because it was in his best interest to have students on his side when they obtained the right to vote. However, a townie running for office who gave a con speech went against his own best interest and, therefore, must have been sincere about what he was saying. On the other hand, if a townie merely gave his opinion, he had nothing to gain by advocating student voting rights: therefore, Ss had no reason to doubt his sincerity. Accordingly, a townie speaker who gave a pro speech to a student audience that was his opinion and a townie speaker who gave a con speech and was running for 
office were judged most trustworthy.

Taken as a whole, these results differ from the traditional finding that the higher the overall credibility of the speaker the greater the opinion change (Hovland, Janis, \& Kelley, 1953) and only partially support the more recent literature on communicator credibility and communication effectiveness. Walster, Aronson, and Abrahams (1966) reported that the perceived vested interest of the speaker influenced how credible the speaker was perceived to be and how effective the communication was. The present study also found that the perceived vested interest of the speaker influenced attributions of credibility, but failed to have any effect on persuasion.

Mills and Jellison (1967) found that the position advocated by the speakers and his perception of how desirable the speech was to the audience also influenced attributions of credibility and communication acceptance. The present study replicated Mills and Jellison's results for communicator credibility but not for persuasion.

The results of the present study in conjunction with previous studies suggest the following empirical conclusions. (a) When Ss have a vested interest (i.e., high ego involvement) in an issue, credibility manipulations that minimize negative attributes of a communicator (e.g., intent to persuade, speaker's vested interest, etc.) will enhance persuasion only when the position advocated is desirable to Ss. When the position advocated is undesirable to Ss, variation in the perception of the communicator's characteristics will be independent of his persuasiveness. Studies by Walster and Festinger (1962) and Brock and Becker (1965) are most pertinent to this point. In both studies, when attribution of persuasive intent was minimal (overheard condition) persuasion was enhanced only when desirable conclusions were advocated. (b) When Ss have no vested interest (i.e., low ego involvement) in an issue, credibility manipulations that minimize negative attributes of a communicator will directly enhance persuasion. Studies by Walster, Aronson, and Abrahams (1966) and Mills and Jellison (1967) seem particularly relevant here. Specifically, Mills and Jellison used an issue (truck licenses) that was of very low relevance for Ss. In this case, when the communicator spoke against his own vested, there was a strong persuasive effect.

In the present study, Ss had a strong vested interest in the student voting issue. Under this condition, only the content of the speech affected persuasion, and variation in trustworthiness and expertise were independent of magnitude of persuasion.

Several important variables need to be studied in more detail, and more research is clearly needed. For one thing, much attention has been focused on perceived vested interest of a communicator. Little attempt has been made to manipulate systematically the vested interest of Ss in the issue. The great bulk of the research on attitude change has used innocuous, unimportant issues. It may well be that the generalization that "high credibility enhances persuasion" was valid only for such innocuous issues. Communicator credibility may be of only slight importance when the issues are important and a definite initial position is held by Ss.

As a second point, most of the older literature on credibility used high- and low-credible sources with whom Ss had little personal acquaintance. The present study explicitly varied the social similarity of the speaker within the context of personal acquaintance with both types of speakers (students or townspeople). Similar speakers received higher overall ratings for trustworthiness and expertise than a townie speaker. However, a glance at Fig. 1 indicates that strong differentiation of attributions was made only for the townie speaker. Why such differing attributions are made for dissimilar but not similar others is not entirely clear and should receive future attention.

In conclusion, the present experiment demonstrates that the simple credibility-persuasion generalization stemming from the older attitude literature is no longer adequate. The relation between credibility and persuasion must be studied under a wide range of variation in $S$ involvement. The technical problem requiring solution is some way of manipulating involvement experimentally without having to depend on initial population differences in issue involvement.

\section{REFERENCES}

Brock, T. C., \& Becker, L. A. Ineffectiveness of "overheard" counter-propaganda. Journal of Personality \& Social Psychology, 1965, 2, 654-660.

Hovland, C. I., Janis, I. L., \& Kelley, H. H. Communication and persausion. New Haven: Yale University Press, 1953.

Mills, J., \&. Jellison, J. M. Effect on opinion change of how desirable the communication is to the audience the cornmunicator addressed. Journal of Personality \& Social Psychology, 1967, 6, 98-101.

Walster, E., Aronson, E., \& Abrahams, D. On increasing the persuasiveness of a low prestige communicator. Journal of Experimental Social Psychology, 1966, 2, 325-342.

Walster, E., \& Festinger, L. The effectiveness of "overheard" persuasive communications. Journal of Abnormal \& Social Psychology, 1962, 65, 395-402.

\section{NOTE}

1. A large number of students completed the attitude scale early in the quarter. The mean value of the sum score for this unexposed control group was 25.90 . This value lay between the pro and con means, as shown in Table 1 , indicating that both the pro and con speeches had some persuasive effect. As might be expected, the effect was somewhat stronger for the pro than for the con message.

(Received for publication May 23, 1973; accepted June 11, 1973.) 